\title{
Status of tuberculosis infection control programs in Canadian acute care hospitals, 1989 to 1993 - Part 1
}

Donna Holton MD, Shirley Paton MN, Helen Gibson MD, Geoffrey Taylor MD, Carol Whyman BScN, TC Yang MD

D HOLTON, S PATON, H GIBSON, G TAYLOR, C WHYMAN, TC YANG. Status of tuberculosis infection control programs in Canadian acute care hospitals, 1989 to 1993 - Part 1. Can J Infect Dis 1997;8(4):188-194.

OBJECTIVE: To document tuberculosis (TB) prevention and control activities in Canadian acute care hospitals from 1989 to 1993.

DESIGN: Retrospective questionnaire.

PARTICIPANTS: All members of the Community and Hospital Infection Control Association-Canada and l'Association des professionnels pour la prévention des infections who lived in Canada and worked in an acute care hospital received a questionnaire. One questionnaire per hospital was completed.

OUTCOME: The study documented the number of respiratory TB cases admitted to the hospital, the type of engineering and environmental controls available, and the type of occupational tuberculin skin test (TST) screening programs offered by the hospital.

RESULTS: Questionnaires were received from 319 hospitals. Ninety-nine (32\%) hospitals did not admit a respiratory TB case during the study. Thirty-one (10\%) hospitals averaged six or more TB cases per year. TST results were reported for 47,181 health care workers, and 819 (1.7\%) were reported as TST converters; physicians had a significantly higher TST conversion rate than other occupational groups. Most hospitals did not have isolation rooms with air exhausted outside the building, negative air pressure and six or more air changes per hour. Surgical masks were used as respiratory protection by $74 \%$ of staff.

CONCLUSIONS: Canadian hospitals can expect to admit TB patients. Participating hospitals did not meet TB engineering or environmental recommendations published in 1990 and 1991. In addition, occupational TB screening programs in 1989 to 1993 did not meet Canadian recommendations published in 1988.

Key Words: Nosocomial infection, Occupational health, Tuberculosis

Statut des programmes de lutte contre la tuberculose dans les hôpitaux canadiens de soins aigus, de 1989 à 1993

OBJECTIF : Retracer les activités de prévention de la tuberculose dans les hôpitaux canadiens de soins aigus 1989 et 1993. MODÈLE : Sondage rétrospectif.

PARTICIPANTS : On a distribué des questionnaires aux membres de la Community and Hospital Infection Control Association-Canada et de l'Association des professionnels pour la prévention des infections vivant au Canada et

voir page suivante

Part 1, Laboratory Centre for Disease Control (LCDC)/Community and Hospital Infection Control Association-Canada Tuberculosis Survey Laboratory Centre for Disease Control, Health Canada, Ottawa, Ontario; Department of Medicine, University of Alberta, Edmonton, Alberta; Infection Control, Kingston General Hospital, Kingston, Ontario

Correspondence: Dr D Holton, 629 Brierwood Avenue, Ottawa, Ontario K2A 2J1. Telephone 613-728-2231, fax 613-728-4319, e-mail dlholton@concentric.net 
œuvrant dans un hôpital de soins aigus. Un questionnaire par hôpital a été rempli.

RÉPONSE: L'étude a servi à documenter le nombre de cas de TB respiratoire hospitalisés, les contrôles techniques et environnementaux disponibles et le type de programmes de dépistage de la TB en milieu de travail reposant sur lest tests à la tuberculine.

RÉSULTATS : Trois cent dix-neuf hôpitaux ont retourné leur questionnaire. Quatre-vingt-dix (32 \%) hôpitaux n'ont admis aucun cas de TB respiratoire durant l'étude. Trente-et-un (10\%) ont déclaré en moyenne six cas de TB ou plus par année. Les résultats des tests à la tuberculine ont été donnés pour 47181 travailleurs de la santé et 819 (1,7\%) ont une conversion de la réaction à la tuberculine; les médecins étaient plus fortement représentés dans cette catégorie que les autres groupes professionnels. La plupart des hôpitaux n'étaient pas dotés de chambres d'isolement munies d'une bouche d'aération vers l'extérieur, d'un système de pression négative et d'au moins six changements d'air par heure. Seulement 13 hôpitaux à haut risque présentaient ces trois caractéristiques techniques. Les masques chirurgicaux ont été utilisés pour la protection respiratoire par $74 \%$ du personnel.

CONCLUSIONS : Les hôpitaux canadiens peuvent s'attendre à admettre des patients tuberculeux. Les hôpitaux participants ne répondaient pas aux normes techniques et environnementales prescrites dans les recommandations publiées en 1990 et 1991. De plus, les programmes de dépistage de la TB en milieu de travail entre 1989 et 1993 ne répondaient pas aux recommandations canadiennes publiées en 1988.

$C^{a}$ anada is one of the few countries in the world that reports fewer than 10 tuberculosis (TB) cases per 100,000 population. From 1987 to 1993 , the Canadian TB rate varied between 6.9 to 7.4 cases per 100,000 persons (1947 to 2108 cases per year) (1). However, this plateau ended decades of decreasing rates. $T B$ is not evenly distributed in Canada, with the TB rates ranging from 1.8 to 53.6 per 100,000 population reported from the provinces and territories in 1993 (1). TB's focal nature in Canada is further illustrated by the wide range of TB rates reported in federal electoral districts (2). Higher rates of TB are reported in specific well-defined Canadian population subgroups, such as Aboriginal Canadians, the elderly and foreign-born individuals (3).

Relatively few cases of drug-resistant TB have been reported in Canada. In 1993, 7\% of TB cases reported in western Canada were resistant to one or more drugs (4). No outbreaks of multidrug-resistant TB (MDR-TB) (ie, resistant to at least isoniazid [INH] and rifampin) have been reported in Canada, though isolated cases have been reported. This differs from the experience in some parts of the United States. For example, in New York City, 26.3\% of new TB cases reported in 1991 were resistant to one or more drugs, and $12.9 \%$ were resistant to at least INH and rifampin (5). MDR-TB outbreaks have been reported in New York and Florida (6).

Increasing concern has been raised about the risk of transmission of Mycobacterium tuberculosis to health care workers (HCWs) in acute care hospitals as the result of several TB outbreaks which occurred in American health care facilities in the late 1980s and the 1990s (6-11). The American hospitals did not meet the TB control measures outlined in the 1990 Centers for Disease Control and Prevention (Atlanta, Georgia) (CDC) TB guidelines (12). Because little information was available about TB control programs in Canadian hospitals, the Laboratory Centre for Disease Control (LCDC), Health Canada and the Community and Hospital Infection Control Association-Canada (CHICA-Canada) initiated a study in 1994 to document the number of respiratory TB cases admitted, the type of engineering and environmental control measures available, and the types of occupational TB screening programs offered by Canadian hospitals.

\section{MATERIALS AND METHODS}

The study steering committee developed a questionnaire, based in part on a questionnaire used in a study performed by the Society of Healthcare Epidemiology of America (SHEA) and the $\mathrm{CDC}$, to document, retrospectively, the number of respiratory TB cases admitted, the type of engineering and environmental control measures available, and the type of occupational TB screening programs offered in Canadian hospitals from 1989 through 1993. Each member of CHICACanada and l'Association des professionnels pour la prévention des infections (APPI) who indicated on the CHICA or APPI membership list that he or she lived in Canada and worked in an acute care hospital received a questionnaire. Instructions were provided requesting that only one questionnaire be completed per hospital. Nonresponders were sent a follow-up letter that included a second copy of the questionnaire. If two or more questionnaires were received from the same hospital, the respondents were contacted and the duplicate questionnaire was discarded.

Respondents answered questions regarding the number of hospital beds; annual number of admissions (total admissions and admissions for respiratory TB and MDR-TB); number of personnel (medical, nursing, respiratory and laboratory staff); results of acid-fast bacilli (AFB) sputum smears (positive, negative or unknown); the type and frequency of occupational tuberculin skin test (TST) screening; results of the screening program; type of personal respiratory protection devices used; isolation facilities and engineering control available; and whether a protocol was in place to triage individuals at high risk of having TB. No data verification was performed.

A hospital was identified as having a TST screening policy if the hospital screened HCWs on hiring or postexposure or had any type of routine TST screening policy (eg, screen every six months, every year, every two years). Individuals found to have a positive TST documented within two years of a documented negative TST were classified as converters (13).

TB was defined as respiratory TB when there was involvement of the lung tissue, respiratory airways or larynx, pleura, or cervical and intrathoracic nodes or when there was disseminated disease (ICD9 codes 010 to 012.8 and 018). MDR-TB 
TABLE 1

Cases of respiratory tuberculosis (TB) reported by acute care hospitals 1989 to $1993(n=319)$

\begin{tabular}{cccccc}
\hline Year & $\begin{array}{c}\text { Total number } \\
\text { of TB cases }\end{array}$ & $\begin{array}{c}\text { Range of cases } \\
\text { admitted to hospitals } \\
\text { reporting TB cases }\end{array}$ & $\begin{array}{c}\text { Number of hospitals } \\
\text { reporting TB cases }\end{array}$ & $\begin{array}{c}\text { Number of hospitals } \\
\text { reporting no TB cases }\end{array}$ & $\begin{array}{c}\text { Number of } \\
\text { nonresponding } \\
\text { hospitals }\end{array}$ \\
\hline 1989 & 724 & $1-113$ & $123(38.6 \%)$ & $167(52.4 \%)$ & $29(9.1 \%)$ \\
1990 & 763 & $1-96$ & $127(39.8 \%)$ & $170(53.3 \%)$ & $22(6.9 \%)$ \\
1991 & 812 & $1-107$ & $136(42.6 \%)$ & $168(52.7 \%)$ & $15(4.7 \%)$ \\
1992 & 872 & $1-119$ & $143(44.8 \%)$ & $163(51.1 \%)$ & $13(4.1 \%)$ \\
1993 & 829 & $1-90$ & $139(43.6 \%)$ & $167(52.4 \%)$ & $13(4.1 \%)$ \\
Total & 4000 & $1-119$ & $38.6 \%-44.8 \%$ & $51.1 \%-53.3 \%$ & $4.1 \%-9.1 \%$ \\
\hline
\end{tabular}

was defined as being present when the organism was resistant to at least INH and rifampin; the definition of MDR-TB was included in the questionnaire. The average number of TB admissions per hospital was calculated by adding the number of TB cases reported for each year by each hospital and dividing by the number of years for which the data were collected.

Data were entered and analyzed using EPI INFO 6.02 (CDC). Categorical data were analyzed using the ${ }^{2}$ test. Significance was determined using either Yates correction coefficient or when the cell sizes were small, a Fisher's exact test. The ${ }^{2}$ test for linear trends was used to assess trends over time. $\mathrm{P}<0.05$ was considered significant.

\section{RESULTS}

Questionnaires were sent to CHICA-Canada and APPI members working in 524 Canadian hospitals. Data were received from $319(60.9 \%)$ hospitals. Only one questionnaire was included from each hospital. Responses were received from hospitals in all provinces and one of the two territories. Seventy-one $(22.3 \%)$ of the participating hospitals were in British Columbia and Alberta, 37 (11.6\%) in Saskatchewan, Manitoba and the Northwest Territories, 122 (38.2\%) in Ontario, $50(15.7 \%)$ in Quebec and $39(12.2 \%)$ in the Atlantic provinces.

Hospital characteristics: Questionnaires were received from 117 hospitals with fewer than 100 beds, 148 hospitals with between 100 and 499 beds, and 34 hospitals with 500 or more beds (mean number of beds 236 , median number of beds 152 , range two to 1466). Nineteen hospitals did not report the number of beds in their facility.

In the 302 hospitals reporting staffing numbers, the mean number of HCWs working in a hospital was 901 (median 504, range 24 to 7500 ). Some hospitals did not report specific numbers of individuals working in each of the staffing categories. In addition, some hospitals indicated they did not have individuals working in all staffing categories. A total of 30,635 physicians worked in 256 hospitals (mean 119.6, median 25, range one to 2000); 102,066 nurses were employed by 290 hospitals (mean 352, median 190.5, range four to 2500); 2240 respiratory staff were employed by 170 hospitals (mean 13.5 , median 8, range one to 99); and 11,453 laboratory staff were employed by 269 hospitals (mean 43.2, median 15, range one to 500$)$.

Table 1 describes TB cases reported by participating hospi- tals. The mean number of TB patients reported in each year of the study among the hospitals reporting TB cases was 6.0 (median 2.0). Forty-eight (15.0\%) hospitals reported admitting at least six TB cases in at least one year of the study. Over the study period, the percentage of hospitals admitting six or more TB cases in a year varied from $5.9 \%$ to $10.2 \%$ of the hospitals reporting data for that year. An average annual TB rate of six or more TB cases per year was reported by 31 (10.0\% $31 / 319$ is $9.7 \%$ which is correct) hospitals (denominator range one to five years). Only one institution (0.3\%) reported admitting an average of more than 100 TB cases per year.

Fifty-one (1.3\%) cases of MDR-TB were reported. From 1989 through 1993 the percentage of TB cases identified as MDR-TB was $1.4 \%, 0.4 \%, 0.4 \%, 1.2 \%$ and $3.0 \%$, respectively ( test for trend 11.0, $\mathrm{P}=0.0009)$. MDR-TB cases were reported in seven of 11 (63.6\%) provinces and territories. MDR-TB cases were reported in $30(9.6 \%)$ hospitals (range one to six MDR-TB cases per hospital).

The percentage of TB cases with AFB sputum smear results reported as positive or negative rather than unknown increased significantly from 1989 to $1993\left({ }^{2}=107, \mathrm{P}=10^{-5}\right)$. Specifically, $35.5 \%$ of TB cases had known AFB sputum smear results in $1989,40.4 \%$ in $1990 ; 42.7 \%$ in $1991 ; 49.7 \%$ in 1992 ; and $59.9 \%$ in 1993 . When AFB smear results were known, the percentage of AFB-positive smears generally decreased over the study period $(65.0 \%$ in $1989 ; 62.3 \%$ in $1990 ; 63.4 \%$ in $1991 ; 61.0 \%$ in 1992; and $57.4 \%$ in 1993), although the trend was not statistically significant $(\mathrm{P}=0.05)$.

TST screening programs: Tables 2 and 3 describe TST screening policies reported for medical, nursing, respiratory and laboratory staff. Fewer than half the participating hospitals reported having TST screening policies for medical staff. More than $70 \%$ of the hospitals had screening policies for nursing, respiratory or laboratory staff (Table 2). One hundred and eighty-eight (59.8\%) hospitals had a written protocol for investigating contacts of TB patients.

In total, TST results were reported for 47,181 HCWs; 819 $(1.73 \%)$ conversions were documented. Conversion rates were calculated for each year of the study for each of the occupational groups (Table 4). Results of TST screening programs were provided by an increasing number of hospitals from 1989 to 1993 . By 1993,33 (10.3\%) hospitals reported results for the medical staff, 106 (33.2\%) for nurses, 45 (26.8\%) for 
TABLE 2

Acute care hospitals performing a tuberculin skin test (TST) at hiring and post-tuberculosis exposure

\begin{tabular}{|c|c|c|c|c|c|c|}
\hline \multirow[b]{2}{*}{ Staff category } & \multirow[b]{2}{*}{$\begin{array}{l}\text { Hospitals } \\
\text { with staff } \\
\text { category }\end{array}$} & \multirow[b]{2}{*}{$\begin{array}{l}\text { Hospitals } \\
\text { reporting no } \\
\text { exisiting policy }\end{array}$} & \multirow[b]{2}{*}{$\begin{array}{l}\text { Hospitals } \\
\text { with } \\
\text { TST policy }\end{array}$} & \multicolumn{3}{|c|}{ Hospitals with TST screening policies } \\
\hline & & & & $\begin{array}{l}\text { Hospitals with } \\
\text { policy to TST test } \\
\text { at hiring }\end{array}$ & $\begin{array}{l}\text { Hospitals with } \\
\text { postexposure } \\
\text { policy }\end{array}$ & $\begin{array}{l}\text { Hospitals with } \\
\text { hiring and post- } \\
\text { exposure policies }\end{array}$ \\
\hline Medical staff & 319 & $61(19.1 \%)$ & $154(48.2 \%)$ & $\begin{array}{c}91(59.0 \%) \\
40(44.0 \%) \text { one-step } \\
32(35.2 \%) \text { two-step }\end{array}$ & $124(80.5 \%)$ & $64(41.5 \%)$ \\
\hline Nursing staff & 319 & $23(7.2 \%)$ & $229(71.8 \%)$ & $\begin{array}{c}202(88.2 \%) \\
92(45.5 \%) \text { one-step } \\
73(36.1 \%) \text { two-step }\end{array}$ & $190(83.0 \%)$ & $168(73.4 \%)$ \\
\hline Respiratory staff & 170 & $12(7.0 \%)$ & $123(72.3 \%)$ & $\begin{array}{c}101(82.1 \%) \\
45(44.6 \%) \text { one-step } \\
40(39.6 \%) \text { two-step }\end{array}$ & $110(89.4 \%)$ & $92(74.8 \%)$ \\
\hline Laboratory staff & 269 & $22(8.2 \%)$ & 189 (70.3\%) & $\begin{array}{c}160(84.7 \%) \\
74(46.3 \%) \text { one-step } \\
57(35.6 \%) \text { two-step }\end{array}$ & $152(80.4 \%)$ & $128(67.7 \%)$ \\
\hline
\end{tabular}

TABLE 3

Frequency of ongoing tuberculin skin test (TST) screening in acute care hospitals with a TST screening policy

\begin{tabular}{|c|c|c|c|c|c|c|}
\hline Staff category & $\begin{array}{c}\text { Every six } \\
\text { months (\%) }\end{array}$ & $\begin{array}{c}\text { Every year } \\
(\%)\end{array}$ & $\begin{array}{c}\text { Every } \\
\text { two years (\%) }\end{array}$ & $\begin{array}{c}\text { Other interval } \\
(\%)\end{array}$ & $\begin{array}{c}\text { Not done } \\
(\%)\end{array}$ & $\begin{array}{c}\text { No response } \\
(\%)\end{array}$ \\
\hline Medical staff $(n=154)$ & $1(0.6 \%)$ & $23(14.9 \%)$ & $6(3.9 \%)$ & $8(5.2 \%)$ & $82(53.2 \%)$ & $34(22.1 \%)$ \\
\hline Nursing staff $(n=229)$ & $1(0.4 \%)$ & $62(27.1 \%)$ & $10(4.4 \%)$ & $18(7.9 \%)$ & $116(50.7 \%)$ & $22(9.6 \%)$ \\
\hline Respiratory staff $(n=123)$ & $1(0.8 \%)$ & $29(23.6 \%)$ & $3(2.4 \%)$ & $12(9.8 \%)$ & $66(53.7 \%)$ & $12(9.8 \%)$ \\
\hline Laboratory staff (n=189) & $2(1.1 \%)$ & $53(28.0 \%)$ & $6(3.2 \%)$ & $17(9.0 \%)$ & $90(47.6 \%)$ & $21(11.1 \%)$ \\
\hline
\end{tabular}

N Number of hospitals with TST policy

respiratory staff and 74 (27.5\%) for laboratory staff. Active TB was identified in one HCW.

Additional analysis was performed on data from 45 hospitals reporting TST screening results for all five years of the study. The median conversion rate reported for each year of the study was zero; however, the percentage of the hospitals that reported converters increased over the study period. This trend was not statistically significant $(31.1 \%, 33.3 \%, 37.8 \%$, $44.4 \%, 44.4 \%$ from 1989 to 1993 , respectively). The yearly pooled average conversion rate decreased from 1989 to 1992 (1.77\%, $1.47 \%, 1.23 \%, 1.19 \%)$ but increased in 1993 (1.55\%).

Clusters of conversions (two or more conversions occurring in one area in a three-month period) were reported in 22 of 307 (7.2\%) hospitals. A source for the cluster was identified in nine clusters (40.9\%), not identified in 10 (45.5\%), and not stated in three (13.6\%). Two to $13 \mathrm{HCWs}$ converted per cluster.

Over the five-year period, INH prophylaxis was given to 227 of $819(27.7 \%)$ converters. The percentage of converters who were prescribed INH increased over the study period $\left({ }^{2}=27.0, \mathrm{P}<10^{-5}\right)$. Specifically, $29.0 \%$ of converters were given INH in $1989,24.5 \%$ in $1990,35.3 \%$ in $1991,36.9 \%$ in 1992 and $41.2 \%$ in 1993 . Respiratory staff were most likely to be prescribed INH (54.2\%), followed by laboratory staff (36.2\%) and nursing staff (33.4\%); medical staff converters were least likely to be prescribed INH (28.3\%). These differences were not statistically significant.
Isolation facilities: The number of participating hospitals reporting the presence or absence of six types of engineering or environmental control measures commonly believed to limit TB transmission are presented in Table 5. Hospitals did not always indicate the presence or absence of each engineering or environmental control measures. Two hundred and fifty-five hospitals answered whether at least one room on a ward had air exhausted to the outside, had negative air pressure and had six or more air changes per hour. Only 55 hospitals reported the presence of all three measures. Two hundred and seventyeight hospitals indicated whether they had an isolation room on a ward with the air exhausted outside the building and negative air pressure. Seventy-eight hospitals had both control measures. Eighty-two of 319 hospitals (25.7\%) reported having a written protocol to identify patients at high risk of having TB.

Respiratory protective devices: Information about the type of face mask or personal respiratory protection used by HCWs was provided by 282 hospitals; 209 (74.1\%) hospitals used surgical masks, $70(24.8 \%)$ used personal respirators and three (1.1\%) stated that no personal protection was provided. Two of the latter hospitals did not report any TB cases.

\section{DISCUSSION}

A study examining TB hospital readiness was conducted in the United States by SHEA and CDC (14). The results of this study frequently differ. The differences likely reflect differ- 
TABLE 4

Pooled average tuberculin skin test conversion rates by occupational group (all hospitals)

\begin{tabular}{|c|c|c|c|c|c|c|}
\hline 1989 & 1989 & 1990 & 1991 & 1992 & 1993 & All years \\
\hline All occupations & $2.0 \%(183 / 9276)$ & $1.5 \%(147 / 9987)$ & $1.5 \%(133 / 8983)$ & $1.6 \%(130 / 8267)$ & $\begin{array}{c}2.1 \% \\
(226 / 10,668)\end{array}$ & $\begin{array}{c}1.7 \% \\
(819 / 47,181)\end{array}$ \\
\hline Medical staff & $5.9 \%(12 / 204)$ & $3.1 \%(7 / 227)$ & $3.2 \%(13 / 409)$ & $2.2 \%(8 / 372)$ & $3.5 \%(13 / 374)$ & $3.3 \%(53 / 1586)$ \\
\hline Nursing staff & $1.9 \%(159 / 8297)$ & $1.4 \%(129 / 8924)$ & $1.4 \%(109 / 7807)$ & $1.5 \%(109 / 7241)$ & $2.0 \%(189 / 9357)$ & $\begin{array}{c}1.7 \% * * \\
(695 / 41,626)\end{array}$ \\
\hline Respiratory staff & $3.3 \%(7 / 215)$ & $1.0 \%(2 / 204)$ & $2.1 \%(5 / 236)$ & $2.0 \%(4 / 197)$ & $1.8 \%(6 / 331)$ & $20 \% * *(24 / 1183)$ \\
\hline Laboratory staff & $0.9 \%(5 / 560)$ & $1.4 \%(9 / 632)$ & $1.1 \%(6 / 531)$ & $2.0 \%(9 / 457)$ & $3.0 \%(18 / 606)$ & $1.7 \% *(47 / 2786)$ \\
\hline
\end{tabular}

${ }^{*} P<10^{-3} ;{ }^{* * P}<0.05 ;{ }^{+}$Medical staff compared with each of the other occupational groups

TABLE 5

Engineering and environmental measures present in acute care hospitals (1993)

\begin{tabular}{|c|c|c|c|c|c|c|c|c|}
\hline & \multicolumn{2}{|c|}{ Ward $(n=319)$} & \multicolumn{2}{|c|}{$\begin{array}{l}\text { Emergency room } \\
\quad(n=250)\end{array}$} & \multicolumn{2}{|c|}{$\begin{array}{l}\text { Intensive care unit } \\
\quad(n=208)\end{array}$} & \multicolumn{2}{|c|}{$\begin{array}{l}\text { Bronchoscopy suite } \\
(n=131)\end{array}$} \\
\hline & Yes & No & Yes & No & Yes & No & Yes & No \\
\hline Air exhausted to outside & $49.2 \%$ & $39.2 \%$ & $33.2 \%$ & $60.8 \%$ & $51.0 \%$ & $42.3 \%$ & $36.6 \%$ & $54.2 \%$ \\
\hline Negative air pressure & $29.5 \%$ & $62.7 \%$ & $10.8 \%$ & $88.0 \%$ & $31.3 \%$ & $67.8 \%$ & $13.7 \%$ & $82.4 \%$ \\
\hline $\begin{array}{l}\text { Six or more air changes } \\
\text { per hour }\end{array}$ & $36.7 \%$ & $43.7 \%$ & $36.0 \%$ & $51.6 \%$ & $48.1 \%$ & $37.5 \%$ & $45.8 \%$ & $41.2 \%$ \\
\hline Ultraviolet light & $0.9 \%$ & $90.3 \%$ & $0.4 \%$ & $94.0 \%$ & $0.5 \%$ & $94.2 \%$ & $13.0 \%$ & $84.0 \%$ \\
\hline $\begin{array}{l}\text { High-efficiency } \\
\text { particulate air filtration }\end{array}$ & $6.9 \%$ & $84.0 \%$ & $6.4 \%$ & $90.4 \%$ & $9.6 \%$ & $85.1 \%$ & $13.0 \%$ & $84.0 \%$ \\
\hline Anteroom present & $35.7 \%$ & $56.1 \%$ & $3.6 \%$ & $92.0 \%$ & $24.5 \%$ & $70.7 \%$ & $3.8 \%$ & $89.3 \%$ \\
\hline
\end{tabular}

$\mathrm{N}$ Number of hospitals reporting having this type of unit

ences in the hospitals represented in the study populations. In both studies, only members of specific infection control organizations received a questionnaire. However, CHICACanada and APPI both have a broad membership which includes nurses, laboratory staff, physicians and statisticians compared with the more limited membership of SHEA. At the time of the SHEA-CDC study, SHEA membership was limited to physicians and individuals with a doctorate in statistics or epidemiology. While both studies are likely to have members working in large hospitals, smaller hospitals may have been excluded from participating in the SHEA-CDC study.

There was broad participation in our study. Questionnaires were sent to 524 of Canada's 1189 acute care hospitals (44.1\%). Responses were received from 319 (60.9\%) of the 524 hospitals, $16 \%$ of all acute care hospitals in Canada with fewer than 100 beds, $36 \%$ of hospitals with between 100 and 499 beds, and $55 \%$ of hospitals with 500 or more beds (15). Hospitals in 11 of 12 Canadian provincial and territorial jurisdictions participated.

It is reasonable to assume that a high percentage of the TB cases reported in Canada from 1989 to 1993 were identified in this study. The number of TB cases reported in the Canadian Tuberculosis Reporting System from 1989 to 1993 was 10,144 , of which 7591 were classified as respiratory TB (1,16-19). Four thousand respiratory TB cases were identified in this study. TB rates in Canada have remained stable since 1987. Similarly, the proportion of participating hospitals ad- mitting TB patients in any year of the study did not change. In the SHEA-CDC study, 13,165 TB cases were identified in hospitals from 38 (76\%) states (15). The United States reported 102,152 TB cases during the SHEA-CDC study period (1989 to 1992) (20).

More than $30 \%$ of participating hospitals did not admit any individuals with respiratory $\mathrm{TB}$ during the five-year study. Only 48 (11.6\%) hospitals admitted six or more individuals with respiratory TB in any year of the study. These results are markedly different from those reported in the SHEA-CDC study, where only three of 186 (2\%) hospitals did not admit any individuals with TB during their four-year study (14). Based on preliminary results of this study, recommendations in Health Canada's Guidelines for preventing the transmission of tuberculosis in Canadian health care facilities and other institutional settings (21) have attempted to reflect the great variation in the number of TB cases admitted to different hospitals in Canada. The low percentage of TB cases $(1.3 \%)$ reported to be MDR-TB is consistent with other results recently reported in Canada (4).

AFB sputum smear results are an important determinant of a patient's infectivity level and were frequently unknown. The trend of fewer AFB sputum smears being identified as "results unknown" may reflect recall bias or increased awareness of TB issues, which resulted in better reporting of sputum smear results.

More than $70 \%$ of the participating hospitals described TST 
screening policies for nursing, respiratory or laboratory staff, although only $48.2 \%$ had policies concerning medical staff. In 1988, the Canadian Tuberculosis Standards (13) recommended that HCWs be screened for exposure to M tuberculosis. The Canadian TB guidelines (21) published in 1996 goes further and recommends that all individuals who perform work (paid or unpaid) in a hospital should participate in a TST program by having their baseline TB infection status recorded (eg, two-step TST negative, documented TST positive, previously active TB case or inactive TB). In addition, all individuals who have a significant unprotected contact with an individual with active, infectious TB should be evaluated following exposure. This study suggests that the relationship between the medical staff and a hospital's occupational health program needs to be better delineated so that policies concerning medical staff TST screening can be established and implemented.

HCWs' conversion rate data need to be interpreted with caution because of the small number of hospitals reporting TST screening results. The average conversion rates reported in this study varied from $1.5 \%$ to $2.1 \%$ in any year (average for the study $1.7 \%$ ). These rates were similar to the results summarized by Menzies et al (22), although they are higher than the rates reported in the SHEA-CDC study (15). High conversion rates in the medical staff may reflect a self-selection bias in participating in the TST screening programs or increased risk of exposure to $M$ tuberculosis during high risk procedures such as bronchoscopy. Our study did not attempt to differentiate community-acquired infection from nosocomial-acquired infection with $M$ tuberculosis.

A number of other hypotheses may explain the higher conversion rate found in this study compared with the SHEA-CDC study. The United States has never recommended the use of Bacille bilié de calmette-Guérin (BCG) vaccine as part of routine childhood vaccination. Before 1980, BCG vaccine was routinely administered to children and health care professionals in some Canadian jurisdictions. BCG vaccination usually results in a positive TST. Individuals who have a positive TST gradually lose their ability to respond to tuberculin over time. Individuals who have waning immunological memory can redevelop a positive TST if they are challenged by a second TST (ie, they demonstrate the boosting phenomena). Initially performing two TST tests on an individual within a short time period allows the boosting phenomena to be distinguished from new infection with $M$ tuberculosis. Individuals found to have a negative TST using a on-estep baseline TST who are subsequently retested within two years and found to have a positive tuberculin skin test may have boosted or converted (become newly infected with $M$ tuberculosis). Without a baseline twostep TST, individuals who are boosting cannot be distinguished from individuals who are newly infected. Because of previous differences in BCG vaccination use, more individuals in Canada are likely to demonstrate the boosting phenomena than individuals in the United States. In our study, initial two-step TST testing frequently was not performed (Table 2); thus, conversion rates may be artificially increased. Individuals who initially had a negative TST and who were found to have a positive TST when tested three months to two years af- ter the first TST should have been reported as converters. Increased use of two-step baseline TST testing will help separate individuals who are boosting from individuals who are newly infected with $M$ tuberculosis.

Other scenarios may have resulted in individuals being inappropriately reported as converters. According to the definition in the Canadian Tuberculosis Standards $(3,13)$, only individuals who developed a new positive TST result within two years of a negative TST test should be classified as converters. Individuals who have a positive TST the first time they are tested are not converters. Individuals who develop a positive TST more than two years after they had a negative TST should be classified as a new positive and not as converters $(3,13)$. Misclassification may have increased the conversion rate in our study.

Our study found that many isolation rooms, intensive care units, emergency rooms and bronchoscopy rooms did not meet the engineering and environmental control measures recommended in 1990 (12) or 1991 (23) (Table 5). Most participating hospitals did not have isolation rooms with air exhausted outside the building, negative pressure and a minimum of six air changes per hour. The absence of appropriate engineering controls may have contributed to the conversion rates noted above. The Canadian Standards Association (CSA) revised their guidelines for ventilation requirements in health care facilities in March 1991 (24). CSA guidelines differ from the 1990 CDC guidelines in that the CSA recommended a minimum of nine air changes per hour in isolation rooms and a minimum of 12 air changes per hour were recommended in high risk procedure rooms. The new Canadian TB guidelines (21) support the CSA recommendations for all new facilities and recommend that all existing hospitals have a minimum of six air changes per hour in isolation rooms. The Canadian TB guidelines state that TB patients receiving care in an acute care hospital should be cared for in a setting having the appropriate engineering environmental control measures. Hospitals can meet this recommendation either by having rooms with the appropriate engineering and environmental control measures or by transferring the patient to a hospital that has the necessary controls $(21,24)$. From 1989 to 1993, few participating hospitals reported protocols for the early identification and triage of infectious TB cases.

The study period was marked with national and international controversy about the type of personal respiratory devices that would provide HCWs with appropriate protection against infection with $M$ tuberculosis. The controversy concerned whether surgical masks, high efficiency particulate air (HEPA) filter respirators, non-HEPA filter personal respirators or personal powered respirators could provide adequate personal respiratory protection from infection with $M$ tuberculosis. In 1993, 74\% of participating hospitals relied on surgical masks for personal respiratory protection. In 1996, the Canadian TB guidelines attempted to clarify this issue (22). The Canadian TB guidelines recognized that there are insufficient epidemiological data to recommend definitively specific respiratory protection for HCWs (22). However, based on theoretical considerations, protective respiratory devices worn by 
HCWs should filter particles equal to or greater than one micron; have a $95 \%$ filter efficiency tested in the unloaded state; and provide a tight facial seal (less than $10 \%$ facial seal leak).

The study population was a convenience sample, and thus self-selection bias may have occurred. Because data provided by hospitals were gathered retrospectively from hospital records and reports, recall bias may have been introduced. Respondents recorded the number of individuals tested and the number found to have a documented TST conversion. iThe calculated conversion rates may therefore reflect either communityacquired infection or nosocomial-acqured infection with $M$ tuberculosis. The incomplete data available from many hospitals made it difficult to evaluate some aspects of hospital TB prevention and control activities.

\section{CONCLUSIONS}

The results of this study show that from 1989 to 1993 many hospitals in Canada did not have adequate engineering and environmental control measures to prevent the nosocomial transmission of $M$ tuberculosis. In addition, inadequate TST screening practices may not have allowed the identification of $M$ tuberculosis transmission.

ACKNOWLEDGEMENTS: The Committee wishes to thank all the members of CHICA-Canada and APPI who completed the questionnaire form. The Committee gratefully acknowledges the assistance of Susan Matthews and Katherine Lapensée, LCDC, for preparing the manuscript.

\section{REFERENCES}

1. Statistics Canada. Tuberculosis Statistics 1993 [catalogue no 82-220]. Ottawa: Statistics Canada, 1995.

2. Gaudette LA, Ellis E. Tuberculosis in Canada: A focal disease requiring distinct control strategies for different risk groups. Tuber Lung Dis 1993;74:244-53.

3. Standards Committee (Tuberculosis), Canadian Thoracic Society. Canadian Tuberculosis Standards, 4th edn. Ottawa: Canadian Lung Association, 1996.

4. Long R, Fitzgerald M, Fanning A, Cowie R, Hoeppner V, the Western Canada Tuberculosis Group. Antituberculous drug resistance in western Canada (1993-94). Am J Respir Crit Care Med 1995;151:A513. (Abst)

5. Bloch AB, Cauthen GM, Onorato IM, et al. Nationwide survey of drug-resistant tuberculosis in the United States. JAMA 1994;271:665-71.

6. Centers for Disease Control and Prevention. Nosocomial transmission of multi-drug resistant tuberculosis among HIV-infected persons - Florida and New York, 1988-1991. MMWR 1991;40:585-91.
7. Coronado VG, Beck-SaguJ CM, Hutton MD, et al. Transmission of multi-drug-resistant Mycobacterium tuberculosis among persons with human immunodeficiency virus infection in an urban hospital: Epidemiologic and restriction fragment length polymorphism analysis. J Infect Dis 1993;168:1052-5.

8. Pearson ML, Jereb JA, Frieden TR, et al. Nosocomial transmission of multidrug-resistant Mycobacterium tuberculosis: A risk to patients and health care workers. Ann Intern Med 1992;117:191-6.

9. Beck-SaguJ C, Dooley SW, Hutton MD, et al. Hospital outbreak of multidrug-resistant Mycobacterium tuberculosis infections: factors in transmission to staff and HIV-infected patients. JAMA 1992;268:1280-6.

10. Edlin BR, Tokars JI, Grieco MH, et al. An outbreak of multidrug-resistant tuberculosis among hospitalized patients with the acquired immunodeficiency syndrome. $\mathrm{N}$ Engl J Med 1992;326:1514-21.

11. Jarvis WR. Nosocomial transmission of multidrug-resistant Mycobacterium tuberculosis. Res Microbiol 1993;144;2:117-22.

12. Centers for Disease Control and Prevention. Guidelines for preventing the transmission of tuberculosis in health care settings, with special focus on HIV-related issues. MMWR 1990;39:1-29.

13. Standards Committee (Tuberculosis), Canadian Thoracic Society. Canadian Tuberculosis Standards. 3rd edn. Ottawa: Canadian Lung Association, 1988.

14. Fridkin SK, Manangan L, Bolyard E, et al. SHEA-CDC TB Survey, Part 1: Status of TB infection control programs at member hospitals, 1989-1992 and Part 2: Efficacy of TB infection control programs at member hospitals, 1992. Infect Control Hosp Epidemiol 1995;16:129-40.

15. Canadian Hospital Association. Guide to Canadian Health Care Facilities. Canadian Hospital Association, 1993.

16. Statistics Canada. Tuberculosis Statistics 1990 [catalogue no 82-003S10]. Health Reports Supplement. Ottawa: Statistics Canada, 1992.

17. Statistics Canada. Tuberculosis Statistics 1991 [catalogue no 82-220]. Ottawa: Statistics Canada, 1993.

18. Statistics Canada. Tuberculosis Statistics 1992 [catalogue no 82-220]. Ottawa: Statistics Canada, 1994.

19. Statistics Canada. Tuberculosis Statistics 1989 [catalogue no 82-003S]. Ottawa: Statistics Canada, 1991.

20. Centers for Disease Control and Prevention. Reported Tuberculosis in the United States, 1993. Atlanta: CDC, 1994

21. Health Canada. Guidelines for preventing the transmission of tuberculosis in Canadian health care facilities and other institutional settings. Can Commun Dis Rep 1996;22(Suppl 1):1-54.

22. Menzies D, Fanning A, Yuan L, et al. Tuberculosis among health care workers. N Engl J Med 1995;332:92-8.

23. Canadian Standards Association (CSA). Special Requirements for Heating, Ventilation, and Air Conditioning (HVAC) Systems in Health Care Facilities: A national standard of Canada [CAN/CA-Z317.2-M91]. Rexdale: CSA, 1991.

24. Holton D, Paton S, Gibson H, et al. Comparison of TB infection control programs in Canadian hospitals categorized by size and risk of exposure to TB patients, 1989 to 1993 - Part 2. Can J Infect Dis 1997;8:195-201. 


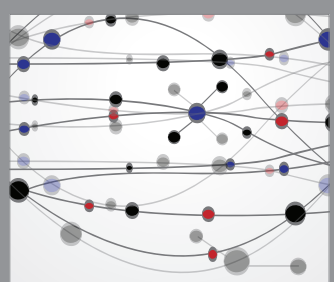

The Scientific World Journal
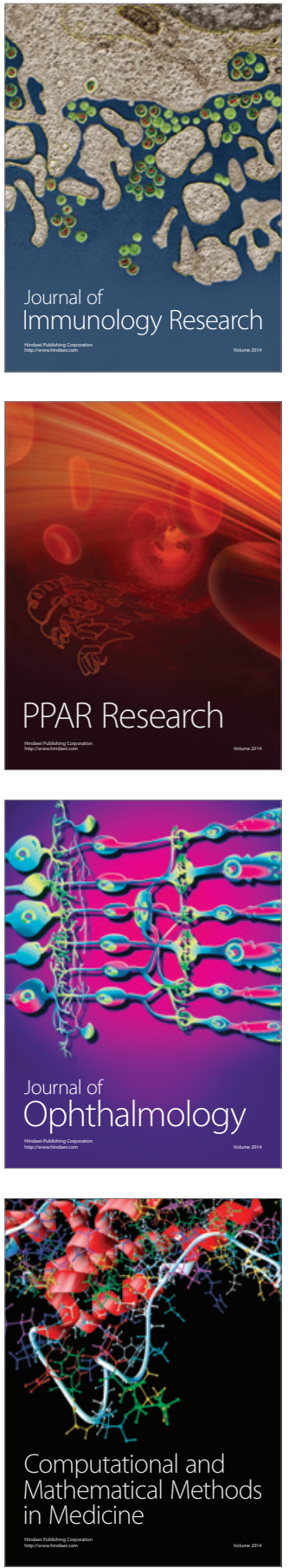

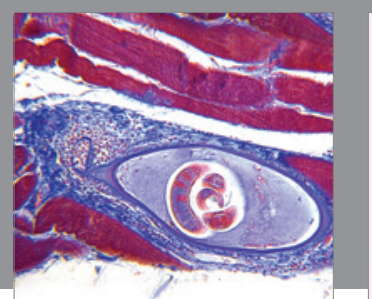

Gastroenterology Research and Practice

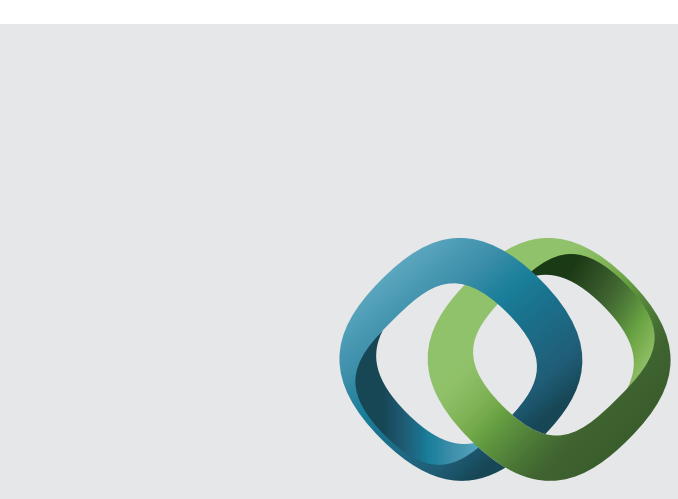

\section{Hindawi}

Submit your manuscripts at

http://www.hindawi.com
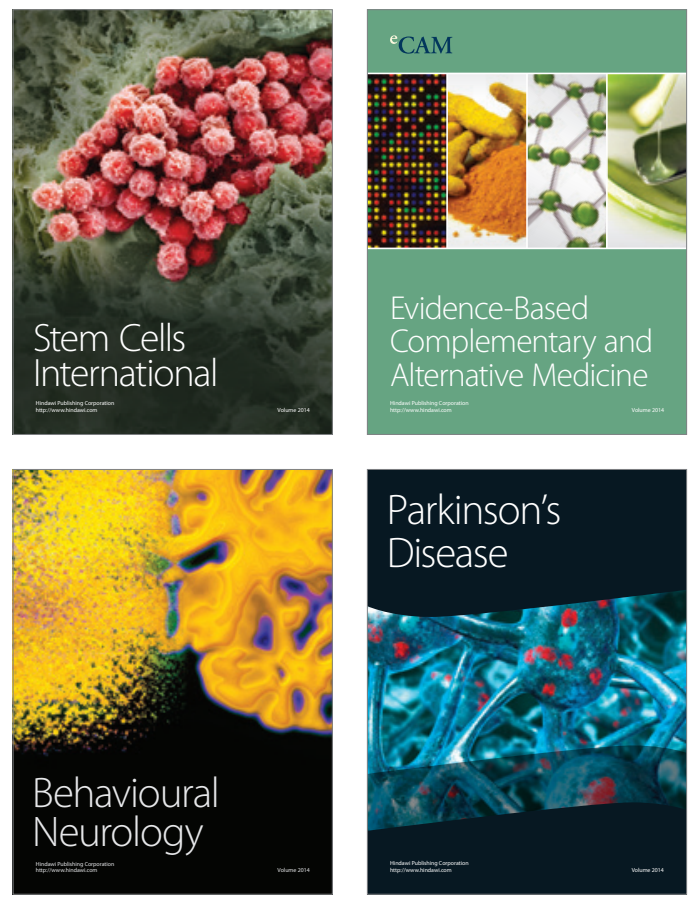
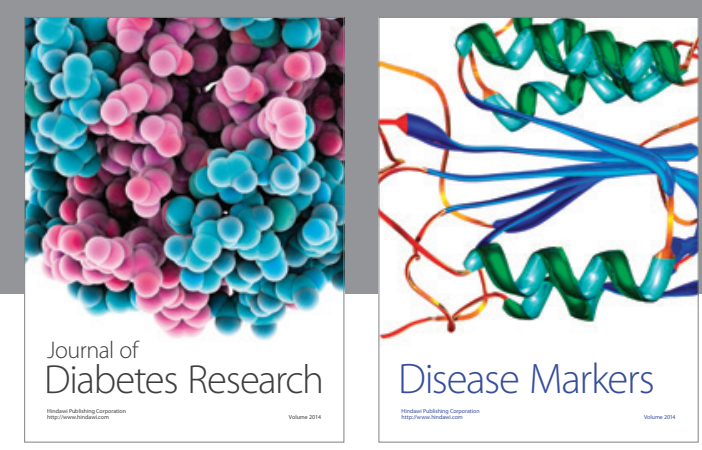

Disease Markers
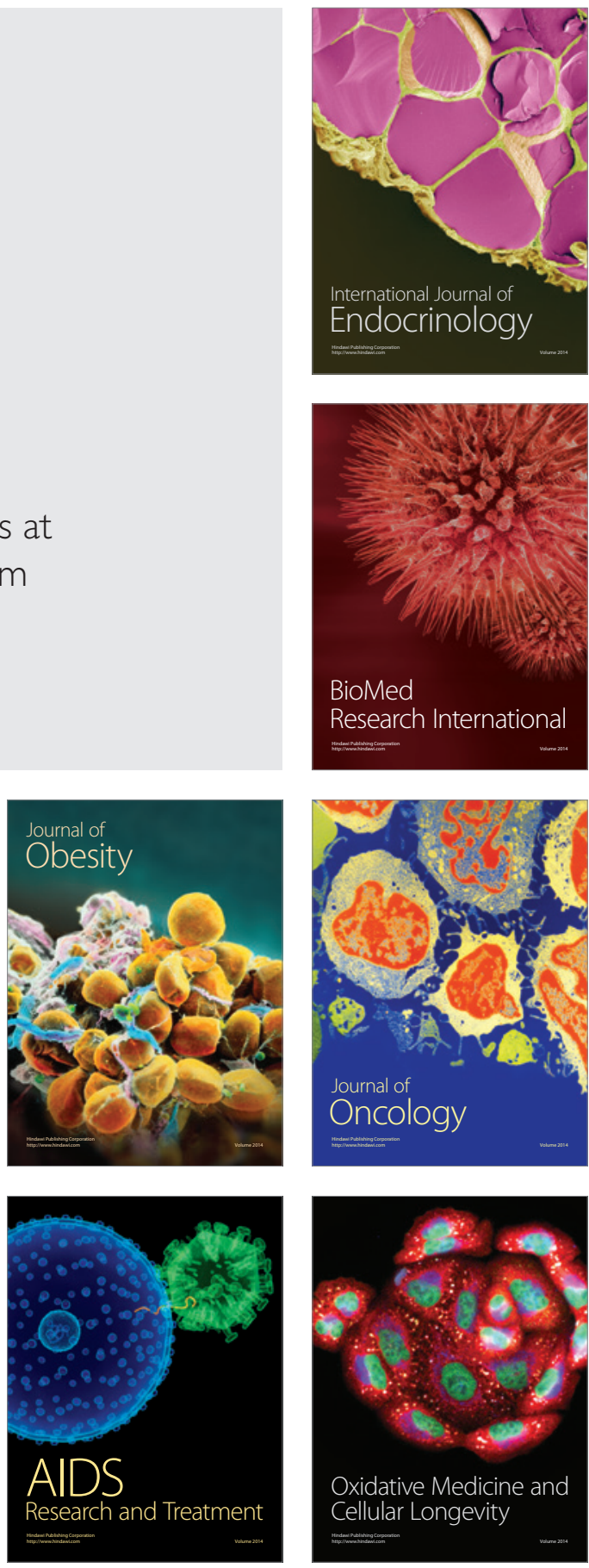